\title{
450019 - ACCELEROMETER-BASED MUSCLE-STIMULATION NEUROMUSCULAR BLOCKADE MONITORING: A PILOT STUDY
}

\author{
William McKay, MD, Ayoub Dangor, MD, Garrett Chin, BSc \\ Anesthesia, University of Saskatchewan, Saskatoon, SK, Canada
}

Introduction: Recent findings suggest that stimulation of intramuscular nerves by surface stimulating electrodes over muscle bellies instead of directly over peripheral nerves could be used to monitor pharmacologic neuromuscular blockade.[1,2,3] Accelerometer-based assessment of the strength of response to peripheral nerve stimulation has been shown to be clinically useful. This experiment compares stimulation over biceps muscle bellies using a commercially available accelerometer-based nerve stimulator (ABNS) with traditional ulnar nerve stimulation at the wrist sensed by a force transducer.

Methods: With Research Ethics Board approval, 10 consenting adults booked for elective surgery under general anesthetic that normally requires paralysis were recruited. The commonest and most-studied stimulation pattern for traditional nerve stimulators, the "train-of-four" (TOF, a set of $40.2 \mathrm{~ms}$ supra-maximal stimuli at $2 \mathrm{~Hz}$, followed by a ten second pause) stimulating the ulnar nerve at the wrist was used. A force transducer was attached to the thumb of the splinted hand. The thumb was abducted to a resting force of $250+/-50 \mathrm{~g}(2.45 \mathrm{~N})$. This standard method of TOF with force transducer (S-TOF) was applied to the left upper limb abducted on an arm board. The ABNS was attached with the accelerometer placed at the midpoint of the left biceps, midway between stimulating electrodes $10 \mathrm{~cm}$ apart on the long axis of the muscle. The ratio of the 4th to 1st TOF ratio S-TOF was compared to the TOF ratio generated by a TOF-Watch ${ }^{\circledR}$ ABNS (ATOF).

Results: Ten subjects were recruited, 5 male and 5 female; age $43 \pm 15$ years; $169 \pm 7 \mathrm{~cm}$ tall; and weighing $83 \pm 18 \mathrm{~kg}$. Regression of A-TOF on simultaneous S-TOF: $\mathrm{R}^{2}=0.54 ; \mathrm{P}$ $<0.001$. Bland and Altman analysis: mean difference $=0.48$ percent; $1.96 \mathrm{SD}=53.3$ percent; three points lie beyond the 1.96SD limits (see graph).

Discussion: The TOF-Watch ${ }^{\circledR}$ used with muscle-belly stimulation and sensing is not a reliable neuromuscular monitor. However, we observed that there was often visible twitching when the TOF-Watch TOF registered zero. This may be because the TOFWatch accelerometer is one-dimensional. We will next investigate whether a 3dimensional accelerometer can give more-useful information.

References: [1] Can J Anesth 2003; 50:342-347 [2] Can J Anesth 2003 50: 864-865. [3] J Clin Monit 1999; 15: 341 - 345 
Bland \& Altman Plot

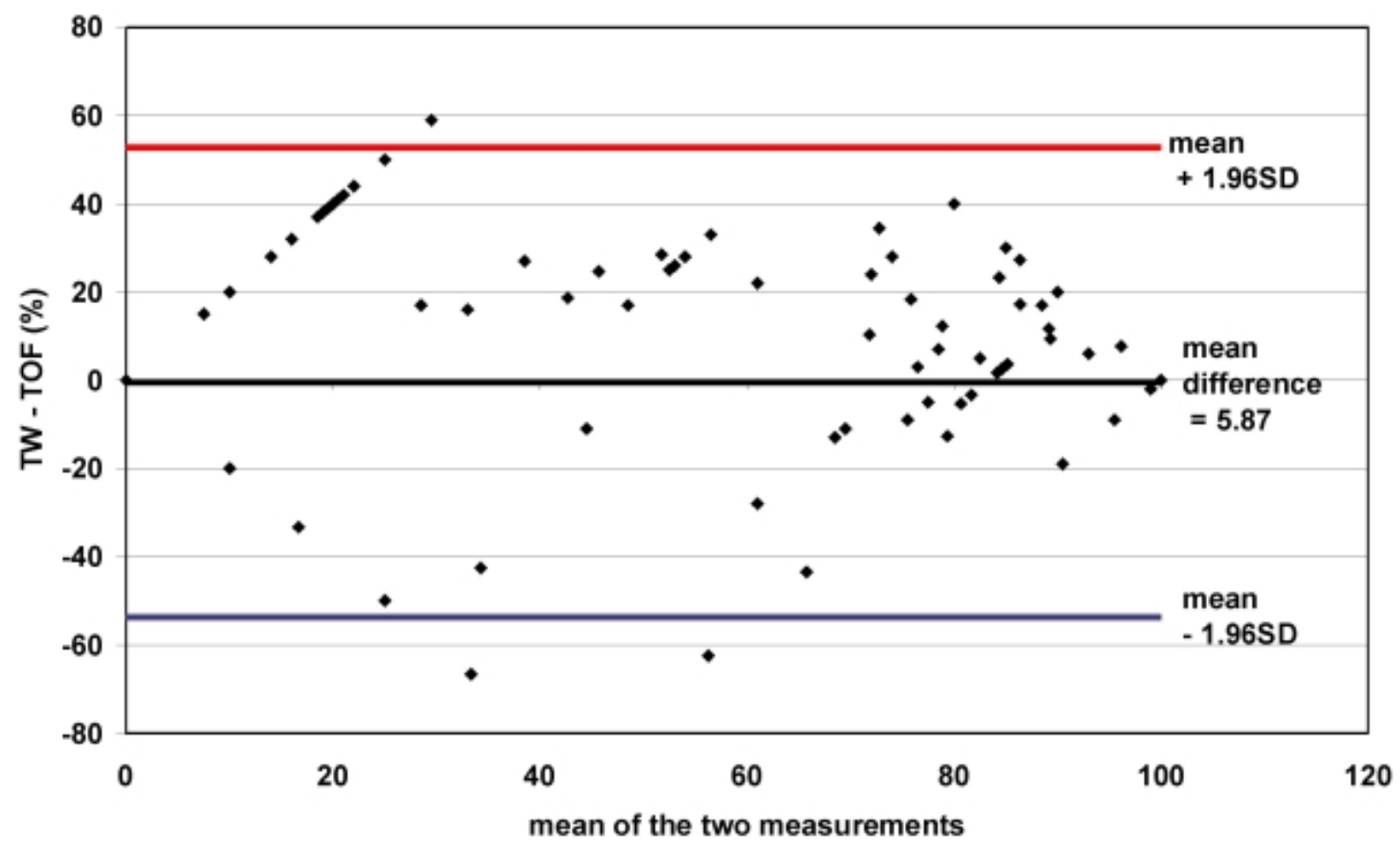

